This item was submitted to Loughborough's Research Repository by the author.

Items in Figshare are protected by copyright, with all rights reserved, unless otherwise indicated.

\title{
Determinants of clinician adoption of regenerative therapies in the UK and Canada: an ophthalmology perspective
}

\section{PLEASE CITE THE PUBLISHED VERSION}

http://dx.doi.org/10.2217/rme.14.82

\section{PUBLISHER}

(C) Future Medicine Ltd

\section{VERSION}

AM (Accepted Manuscript)

\section{PUBLISHER STATEMENT}

This work is made available according to the conditions of the Creative Commons Attribution-NonCommercialNoDerivatives 4.0 International (CC BY-NC-ND 4.0) licence. Full details of this licence are available at: https://creativecommons.org/licenses/by-nc-nd/4.0/

\section{LICENCE}

CC BY-NC-ND 4.0

\section{REPOSITORY RECORD}

Rose, James B., Michael May, and David J. Williams. 2019. "Determinants of Clinician Adoption of Regenerative Therapies in the UK and Canada: An Ophthalmology Perspective". figshare. https://hdl.handle.net/2134/18396. 
Determinants of Clinician Adoption of Regenerative Therapies in the UK and

2 Canada: An Ophthalmology Perspective

4 5

\section{Summary}

The determinants of adoption of regenerative medicine therapies are currently poorly understood. This study aims to draw comparison between the UK and Canada in terms of factors likely to affect healthcare adoption of future regenerative therapies in ophthalmology. Conducting semi-structured interviews with senior ophthalmologists in the UK and Canada, their perceptions of factors either enabling or limiting adoption were recorded and analysed. A number of key concepts were extracted from the interview data which were perceived by stakeholders to contribute to adoption. The core factors developed in this work will be of use to those looking to understand the opportunities and risks involved in securing clinician adoption in both the UK and Canada.

\section{Keywords}

Adoption, Reimbursement, UK, NHS, Canada, Ophthalmology, Translation

\section{Article}

\subsection{Introduction}

Adoption of regenerative medicine (RM) therapies is relatively unchartered territory, with few approved demonstrators having secured reimbursement. In ophthalmology there are a variety of indications in which RM and more specifically cell therapy would offer very real benefit $[1,2]$. However, for these benefits to be realised, therapy developers must 
understand the drivers and potential determinants of uptake into healthcare. This will be

critical to the development of the industry sector and core both to affording widespread

patient access to these therapies, and in realising national economic benefit from attracting industry investment [3].

Healthcare markets around the world vary significantly in the way that healthcare is

financed and delivered. Both the UK's National Health Service (NHS) and Canada's Medicare are well appreciated examples of "single-payer" healthcare systems in which healthcare is funded through taxation, and delivered through publicly governed providers [4]. The NHS has been characterised as a slow adopter of medical technologies, described to be behind many other countries in terms of the therapies it provides [5-7].

To understand if the market characteristics of the NHS are a consequence of its operation as a single-payer system, this work has attempted to draw comparisons with Canada. Canada has received more attention in recent years for its long waiting lists for elective surgeries and high prices paid for patented pharmaceuticals $[8,9]$. Both the UK and Canada are world leaders in the basic research of RM, with both countries' governments keen to gain economic benefit from commercially exploiting this exciting area of technology $[10,11]$

Ophthalmology has been a target area of particular interest to therapy developers for several reasons. The eye is a small, enclosed, largely immune-privileged organ, which allows relatively easy surgical access $[12,13]$. Transplant sites can be easily visualized on account of the organs transparency and functional responses to interventions in many cases can be measured non-invasively with confidence [14]. In addition, effective therapeutic doses of cells in ocular clinical indications are likely to be significantly lower than in other disease areas such as cardiac applications or diabetes [15]. The market opportunities for some 
clinical indications in this space are also significant and for commercial developers could offer a "blockbuster" target [16]. For these reasons it is unsurprising that some of the first clinical trials involving the use of cells derived from embryonic stem cells [17] and induced pluripotent stem cells [18] have been in this clinical area.

This work aims to qualitatively compare the factors affecting or likely to affect the translation, early use and system-wide adoption of RM therapies in both the UK and

Canada. The term regenerative medicine has been used throughout to describe advanced medicinal therapies based on gene therapy, cellular therapeutics and tissue engineering [10].

\subsection{Methods}

This study used a qualitative design based on "problem-centered interviews" (PCI) [19]. The data collection phase ran from Jan 2013 to Sept 2013. 22 consultant ophthalmologists with links to RM research programmes were contacted in both the UK and Canada. Respondents were interviewed face-to-face and in cases when this was not possible by telephone. 34 candidates were invited for interview in the UK. 44 candidates were invited in Canada to reach an equal number of participants in both territories (11 participants).

\subsubsection{Data Collection}

An interview framework was developed using results from an unpublished literature review conducted at the start of this work. The interview framework was trialled on a small number of ophthalmologist volunteers, to ensure no areas of questioning were ambiguous or misleading. The $22 \mathrm{PCl}$ lasted on 40 minutes on average and were recorded using an audio recorder. 
3.2.2 Data Processing

$\mathrm{PCl}$ recordings were transcribed verbatim from voice recordings producing 22 transcripts.

Transcripts were interpreted by using the method of qualitative content analysis as described by Mayring [20]. In brief, interview transcripts were analysed together with the audio recording. A first pass of transcripts showed that participants' responses in $\mathrm{PCl}$ could be grounded in one of three potential phases relating to the use RM therapies in healthcare. These were Translation; Early Use and System-wide Adoption. Controlled interpretation was then applied to the categorized passages, paraphrasing and classifying with a code corresponding to a sub-theme. Interview transcripts were then compared with one another to further group sub-themes into descriptive factors, deemed important at a particular stage of the development process. A final controlling phase was performed to ensure that thematic categorization was justified and consistent between entire samples for both UK and Canadian participants. A semi-quantitative analysis of coded data was then carried out allowing a comparison of responses from UK and Canadian participants. This involved recording the frequency at which sub-theme codes were presented in each of the interviews referred to as the grounded value [21]. In addition, the most recurrent codes with the highest grounded values were broken down as either being a "barrier" or an "enabler" to RM adoption, in accordance to the context in which the respondent gave evidence.

\subsection{Results and Discussion}

Participants were approached both in Canada and the UK. Response rates were higher in the 
93

regions. The Canadian sample importantly covered clinicians from Alberta and British

Columbia (BC); and Ontario. Higher response rates in the UK may have been on account of the familiarity of the UK participants with the authors' research group and institutions. The final 22 respondent convenience sample of ophthalmologists was drawn from those who had links to RM research programmes and naturally came from a number of institutions and regions. As might be expected there were differences in the responses given across the sample which appeared to be predicated on the types of institutions within which these ophthalmologists practiced. In general, respondents working for high profile research centres appeared to look favourably on the systems and processes which supported the adoption of new therapies. On the other hand, clinicians coming from smaller centres gave evidence that they were frustrated with the pace of change, the bureaucracy and the amount of justification required to adopt a therapy, which had been used effectively elsewhere.

\subsubsection{Stages of Adoption of Regenerative Medicine in Ophthalmology}

An area of common discussion throughout the interview process was where in the therapy development pathway participants responses were focussed. The transition of a therapy through research and development, clinical trials and into mainstream clinical use of course is not linear. Clinicians in both countries had significantly different understandings of how their institutions supported clinical research and managed the processes of clinical adoption (Figure 1).

The respondent sample described three potential phases in which they could engage with an RM therapy. The first, prior to market authorisation involves the clinical translation of a 
therapy in which a clinician decides to engage in use under the constraints research

protocols. The sample described a second potential phase of early use after a therapy had gained market approval, or after being verified under hospital exemption or a "specials" licence in the UK [22]. During this phase, therapies with low levels of evidence supporting their effectiveness could be used by clinicians but were not supported as the first-line treatment and often not formally reimbursed. In general respondents saw this as a means to offer these therapies on a named-patient basis or to small patient numbers. System-wide adoption of new therapies could occur only after suitable assessments of the therapies value to the health system have been carried out. This would normally require some level of formal health technology assessment (HTA).

\subsubsection{Translational Adoption of Regenerative Medicines}

Participants' responses relating to the translation of RM therapies in ophthalmology could be classified into 5 core recurrent themes of importance. These were: trial funding; design and execution of RM trials; trial support and infrastructure; the trial approval process and clinicians' positions and attitude to translation (Figure 2). Factors relating to manufacturing challenges and national research priorities were also mentioned multiple times although with significantly lower frequency (Figure 2A).

Themes of clinician position and attitudes and trial funding were viewed as important by a number of respondents although there were mixed opinions as to whether these were likely to be barriers or enablers to translation of RM therapies. Key differences between the responses of UK and Canadian participants were seen in the areas of trial support and infrastructure and most starkly in the trial approval process. In Canada the research ethics 
board (REB) review process was a recurrent point of discontent for participants. Seven

respondents detailed an extremely slow, highly bureaucratic process which had been a cause of concern for many years.

Seven Canadian respondents in total gave accounts of a process that slowed processes significantly and absorbed applicant's time. Three thought that this may act as a deterrent for clinicians to engage in clinical trials, with one detailing specific issues in a multi-national study that they were part of, commenting "by the time our centre got ethics approval for the trial, the study was nearly two thirds complete" CAR9

It was suggested by two participants that the slow ethics review process in Canada was due to an overtly bureaucratic system, tied down by a requirement for perfect submissions, but also more recently in an expanding scope of the ethics boards. It appeared to many that these processes do not have statutory timescales in place for review; neither do they have the capacity for obtaining a single approval for a multi centred trial.

In contrast only one UK participant detailed issues with the clinical trial application and the associated review process; although for this particular respondent it was a cause of frustration detailing several examples of situations where this has been "rate-limiting" "UKR4 in translating RM therapies. In the UK, the process for ethics approval for clinical trials has changed in recent years [23]. Through a positive collaboration between the ethics review boards across four different approval regulators, health services research in the UK is now upheld with a single UK-wide ethical opinion. Whilst these changes were only explicitly 
noted by one participant, it is possible that such changes have made trial approval in the UK more favourable for research-minded clinicians.

Trial support and infrastructure was another area in which multiple stakeholders disagreed important factor in late stage translation of RM therapies, the responses were more evenly split with nearly as many positive accounts of the UK's clinical trial infrastructure as there the investment of the UK's National Institute for Health Research (NIHR) into infrastructure and clinical trial partnerships.

"When I look around me, in the last five years there has been a massive increase in what the NIHR has funded, and the amount the NIHR is contributing to translation and applied clinical research"

A weakness in translational science has long been a problem for those working in the area of health sciences and technology in the UK. Highlighted as a priority area in the Cooksey report 2006 [24], two gaps were identified in health services research, the first in the translation of basic and clinical research into ideas and products; and the second relating to translating those ideas and products into clinical practice. Over the last 7 years the UK government has increased funding and made organisational installations in an attempt to bridge these gaps in translation $[25,26]$. The authors hypothesise that UK investment into clinical trial research infrastructure in the form of the NIHR Office for Clinical Research Infrastructure (NOCRI) may have some part to play in the more positive reception to trial 
support and infrastructure from UK clinicians. This support has aimed to reduce the risk of

running clinical trials in the UK, with various shared funding streams to help industry and academics operate expensive, complex and resource hungry trials [26].

Another area of key importance was that of trial funding, and funding streams for translational science. Five Canadian participants described favourable translational funding programmes. Canadian clinicians have in certain cases been allowed to indirectly access US

NIH funding as well as Canadian Institute for Health Research (CIHR) funding which has offered a larger funding pool for this translational research.

The complexity of RM trial design and execution was recognised by 12 participants in both clinical endpoint measures being described.

Whilst trial support and infrastructure and trial funding for clinical translation of RM was viewed by many as a barrier, it is important to note that participants from Moorfields Eye Hospital (UK) considered many of these systems to be adequate to support the current need for clinical development of these complex therapies. These participants in general, gave 
more positive responses to questioning concerning translation of RM therapies than those in other centres.

Moorfields eye hospital was designated as one of 12 NIHR biomedical research centres in

2011, with a government investment of over $£ 25$ million to drive translational research [33].

The hospital itself is known worldwide, and is undoubtedly the most widely recognised

centre for ophthalmology in the UK. Moorfields Eye Hospital was considered by two

Canadian participants to give the UK a competitive advantage, in terms of its appeal to industry and the national research output in ophthalmology. However there was a shared viewpoint from three UK participants that it can sometimes be difficult to compete for both private and public grant funding opportunities in ophthalmology given the presence of Moorfields, hinting at the concentration of research taking place there. There was a more even spread of investment in Canada with multiple centres of excellence although each province was perceived to have some centres which excelled in biomedical research and translation.

Throughout the PCl two key cell-therapies were mentioned time and time again. These were limbal epithelial stem cell transplantation (LESCT) for limbal epithelial stem cell deficiency (LESCD) [23], and retinal pigment epithelial (RPE) transplantation for macular degeneration and Stargardt's [17]. 5 examples of RM trials involving these therapies were accounted for in the UK and Canada collectively in the PCl, importantly four of these in the UK (Table 2). 
3.3.3 Early Use of Regenerative Medicines

The term early use has been used to refer to the phase of clinical engagement in which the decision to adopt is likely to be based on lower quality clinical evidence. Typically low numbers of patients will be involved, and the therapy will not have reached a suitable point in its development to be scrutinised through a formal health technology assessment. The core themes emerging from discussion around the early use of RM therapies were: regulatory challenges; the influence of private healthcare; institutional management; bureaucracy involved in delivering novel therapies; and the changes to infrastructure or systems to allow therapies such as RM to be used (Figure 3). Ideas likely to be product specific such as cost, patient volume and risk versus benefit decisions were also raised throughout the interviews (Figure 3A).

It is important to note that throughout this study the assumption has been made that the regulatory stakeholders had been satisfied by product developers. While individual clinicians may have links with the regulators, there is likely to be limited interaction between the broader clinical stakeholder group and regulatory stakeholders. Consequently regulation has not been discussed in detail here although some of the important points captured on this area from the interview process have been presented.

In general, respondents in both the UK and Canada appeared to have similar perspectives on their regulatory environment for RM. Most comments on the pace of the regulatory process in Canada were largely tied to experiences outside of RM. However one participant drew reference to the recent approval of the mesenchymal stem cell product Prochymal ${ }^{\circledR}$. 
Health Canada were the first regulator in the world to approve the therapy, albeit through a

This example of facilitative regulation of an important RM therapy although not in

ophthalmology, represents a critical component of the Canadian RM adoption landscape, and is likely to be attractive to other industry stakeholders looking to enter single-payer markets.

Giving patients early access to therapies can be possible outside of the research setting assuming that the therapy has been approved by the relevant authorities and that authorisation can be secured from clinical management. The authors see early access mechanisms such as "hospital exemption" and "specials" schemes in the UK to offer accelerated routes to the patient and facilitate RM therapies availability in the UK [22]. In addition, the experience gained through their use can often be used in formal development.

Factors relating to local organisation, like attitudes of institutional management, bureaucracy and flexibility of infrastructure and services to accommodate the early use of new therapies were all mentioned more frequently by UK participants than those from Canada. Several accounts from UK participants detailed complex and often unclear processes involving numerous departments each with individual processes 
"The application form is very long and tedious - they [local management] require a lot of information and it is a deterrent for many clinicians. Clinicians really don't have

Related to this, more UK responses described difficulties in installing infrastructure to accommodate the early or low level use of RM. Issues included the need for clean rooms, skilled basic scientists, immunology support and intensive patient monitoring. In certain cases these requirements were seen by UK participants as being prohibitive and unlikely to be cost effective for the small patient numbers.

A supportive management structure was also perceived as a crucial for early use of such novel therapies by both Canadian and UK participants. Three Canadian participants were extremely pleased with their institutional management processes and accounted for two examples of well designed, helpful programs to drive innovation in surgery. One participant from Sick Kids hospital in Toronto described in-house processes to try to drive innovation. One offering was that of a small grant competition where regular prizes of $\$ 10,000$ are granted for proposals relating to testing novel unconventional hypotheses with new medicines. Such a programme undoubtedly shows the intent of management to foster innovation and adoption within their organisation.

The effect of the Canadian private market that exists in Canada was perceived to play a far more important role relative to that in the UK. Many Canadian ophthalmologists appeared to think that approved therapies that were yet to receive codes for reimbursement could be delivered and charged directly to the patient, as an alternative route to offering patients 
access to novel treatments. The potential patient pool is of course limited to those patients who can afford such therapies, but may be an important market access mechanism for a limited number of therapies nonetheless. Private insurance companies were perceived to have a similar outlook in both the UK and Canada employing a high evidence threshold for reimbursement. As a consequence it was unclear to many participants as to whether there would be early reimbursement mechanisms with private insurers for RM Therapies.

\subsubsection{System-wide Adoption of Regenerative Medicines}

After building conclusive evidence of a therapy's safety, efficacy and cost-effectiveness, therapies such as RMs must overcome the hurdle of securing reimbursement, and gaining system-wide adoption. Ophthalmologists understood this phase of adoption to be the ultimate barrier to a therapy's success. The extent to which diffusion or system adoption can occur is predicated on the patient volume, clinical need and the delivery models in place for the therapy. Multiple clinicians perceived that it was likely that RMs in ophthalmology with delivery. The reported themes relevant to system-wide adoption included

- Local Management, such as management attitudes, local budget constraints, overall health of the local institutions finances and its freedom to reallocate resource

- Regional Management, such as policy setting and links to political agenda and government priorities

- Health Technology Appraisal, covering issues with the UK's National Institute for Clinical Excellence (NICE) review process and clinical guidance as well as the less centralised Canadian economic evaluation procedures 
- Reimbursement systems including coding and fee tariffs where appropriate and

There are distinct differences in the way that that decision makers were organized at the local regional and national level in the UK and Canada (Figure 4A). In the UK pricing and reimbursement $(P \& R)$ and health technology assessments $(H T A)$ are carried out at a national level. Regional bodies in the UK, namely clinical commissioning groups (CCGs) would then be concerned with regional budgets and access to medicines. At the local level issues such as service design, local budget management and infrastructure requirements are dealt with. In Canada, each of the 10 provinces has its own governmental control over the management and allocation healthcare resources. Whilst ultimately the provinces are still funded from National government transfers derived from taxation, each provincial healthcare system is autonomous and sets its own healthcare priorities. As a consequence, system-level reimbursement and even technology appraisals will largely be done at a subnational level in Canada.

Large variations in the way healthcare adoption was managed and implemented appeared to be a theme on which both UK and Canadian participants agreed. Whilst such fragmentation may be expected from the Canadian system, made up of independent provincial ministries governing healthcare, the fragmentation and regional and local differences in operations in the NHS was perhaps less expected.

The regional management variations in healthcare were identified by 7 UK participants, underlining the complex and heterogeneous system of healthcare in the NHS. Currently, the

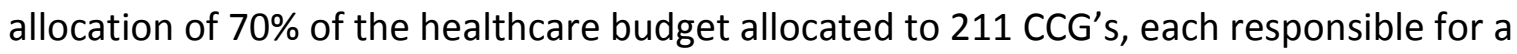
geographic region [27]. Each CCG purchases products and services for long-term conditions 
and common diseases. Therapies targeting rarer diseases involving fewer patients, and

often higher costs are likely to be supported by specialist services commissioning. If albeit in the first instance for low volume therapies.

Organizational inertia was a source of frustration for many respondents working in the NHS with culture and fragmentation given as potential causes. Four UK participants felt that the NHS was particularly unresponsive, and slow to progress in many aspects of care including the uptake of new healthcare technologies.

"There is a traditional way of working [in the NHS] and anything that is going to

No participants in any of the three Canadian provinces sampled, suggested that responsiveness of their provincial health organisations had been an issue.

The biggest differences in responses between the UK and Canada were seen in themes relating to HTA processes, reimbursement systems and local management issues. 10 out of 11 UK participants recognised the importance of NICE's role in the adoption of new therapies. However more were of the opinion that NICE's current capacity, methodologies and practices may not favour RM therapies. Even outside the area of RM, several clinicians recalled instances where slow NICE review had delayed the adoption of approved therapies. retinal vein occlusion. I can't remember when it was available, I think about 2 years 

indications. "UKR8

Only 3 participants could detail processes of HTA or economic evaluation in Canada. One search for HTA of RM in both the UK and Canada identified 4 published HTAs both either reviewed by NICE or by OHTAC (Table 3). Interestingly the two HTA bodies have disagreed on two interventions' cases for adoption. In the use of allogeneic LESCT, both NICE and

OHTAC appeared to disagree as to whether this treatment should be funded. NICE'S assessment reported that there was not enough evidence with respect to the safety and effectiveness of LESCT for the treatment to be offered routinely, but that in cases of a medical necessity special arrangements could be made to offer the treatment [28]. In contrast, OHTAC recommended the treatment for use stating that whilst the evidence to support LESCT is weak, it was considered unlikely given the rarity of the condition, that more robust evidence will be available [29]. The authors hypothesise that this more permissive assessment of LESCT by OHTAC, represents an acknowledgement of the difficulty in running trials with RM therapies in rare diseases, and demonstrates a greater flexibility in terms of HTA. Differences in assessment criteria were also apparent in the two agencies assessments of Islet cell transplantation for type 1 diabetes. It appeared that the approaches taken by the two agencies in determining whether each RM therapy represented value-for-money were very different, perhaps due to varied interpretations of clinical evidence, and different thresholds for acceptable effectiveness. 


\begin{tabular}{lcc}
\hline \multicolumn{1}{c}{ Therapy } & NICE Decision & OHTAC Decision \\
\hline $\begin{array}{l}\text { Autologous limbal cell transplant for limbal cell } \\
\text { deficiency }\end{array}$ & --- & Positive [29] \\
$\begin{array}{l}\text { Autologous limbal cell transplant for limbal } \\
\text { pterygium }\end{array}$ & --- & Negative [29] \\
$\begin{array}{l}\text { Allogeneic limbal cell transplant for limbal cell } \\
\text { deficiency }\end{array}$ & Negative [28] & Positive [29] \\
Islet cell transplantation for type I diabetes & Positive [30,31] & Negative [32] \\
\hline
\end{tabular}

382

Canadian participant's viewed the centralised and highly developed economic evaluations of NICE as more effective at rationing healthcare, and potentially having a well-defined role in the process. Interestingly only three participants could detail processes of health technology appraisal or economic evaluation in Canada. In discussions with UK participants the role of NICE was ultimately central to most responses on system-wide adoption. Whilst for many it was unclear whether RMs targeting some of the rarer conditions would warrant NICE review, its role in adoption was seen as critical. Within scarce NHS resources, it was appreciated that payers need new therapies such as RM to provide value for money. Two UK participants recognised that RM therapies are likely to have very high initial prices but these could drop as expertise and tools for manufacturing and distribution are developed. The initial costs of RM therapies are likely to be a critical factor in their adoption. A report from the UK government recently stated that NICE's assessments should include consideration that early investment in this area could help bring further treatments to the market which may have impact in providing savings in healthcare and in increased investment in the UK [33].

One UK ophthalmologist recognised that RM therapies for rarer diseases may be unsuitable for NICE appraisal and may well be better serviced by specialised services commissioning. 
400

401

402

403

404

405

406

407

408

409

410

411

412

413

414

415

416

417

418

"I think specialist services commissioning is potentially a route to allowing some level of adoption or some level of evaluation, all be it in a constrained fashion. But during that time you've got the opportunity to actually feed the product into the NHS, start to test it, put it through some real world evaluation and see how it works in practice." UKR1

NHS Specialised services were also recognised as an important component of adoption in the 2013 UK government response to the recommendations made in the recent House of Lords Science and Technology Select Committee report on RM. Herein it was noted that a new approach to commissioning services that are currently lacking in evidence would be adopted. The process termed commissioning through evaluation (CtE) would look at services deficient of both clinical and/or cost effectiveness evidence which are thus unsuitable for routine commissioning [33].

When respondents in both the UK and Canada were asked to describe the local and regional decision making processes involved in adopting a new therapy a wide range of responses were recorded. Local and regional processes for uptake of a particular therapy appeared to be varied between different regions. Issues relating to local management in the UK were a cause of concern to several respondents in the UK. Factors including management attitude, patient volume, infrastructure and precedence for the use of similar therapies were all seen to affect the institutional uptake of new therapies.

Whilst the NHS and Canadian health systems share their first principles and some aspects of healthcare organisation (Table 4), the systems have developed significantly different processes for dealing with the uptake of RM therapies (Table 5). Whilst both offer some form of evidence-based healthcare, the two are still guided by value for money, and 
differences in the way that value for money is assessed between the two nations (Table 3)

will be an important area for future exploration.

\subsubsection{Ophthalmology as a Target Clinical Area}

An important feature of this work was the characteristics of the specific clinical group that was

interviewed. A key question to ask was "are there any specific characteristics of ophthalmologists or ophthalmology in general that may impact on any of the three areas investigated. Ophthalmologists perceived themselves to be quieter, less aggressive and on the whole easier to manage than other surgical specialisms (i.e. cardiac surgeons). In addition one participant thought that ophthalmology departments had historically been inward looking located in isolated centres away from other clinical departments.

Many respondents were keen to describe how ophthalmology as a clinical area could offer many benefits as a target site for RM therapies. Such benefits included:

- Measureable outcomes: "...ophthalmology is much more amenable to clinical trials and the outcomes are directly measurable" "AR8. "We are spoilt in ophthalmology by being able to readily assess structure and function..." CAR6

- Isolated organ for targeted therapeutics: "We're really interested in RM in the eye because you can affect the phenotype of cells in the eye locally without affecting it systemically. You could only do this in ophthalmology..." CAR4

- Easy access to test neurological therapeutics: "...for a neurological disease, I think the eye is 
447 The idea that technology and therapies in ophthalmology may evolve quicker than other surgical based clinical areas was noted by four participants. quickly. To at least stay at the standard of care, you have to."

With the exception ocular cancers, the majority of indications treated by ophthalmologists are nonfatal, and thus are seen by policy makers as a lower priority, than for instance cardiovascular medicine or cancer care.

\subsection{Conclusions}

The aim of this work was to identify the factors likely to determine adoption of RM therapies in ophthalmology in the UK and Canada. Factors which appeared to be similar between the UK and the comparator, Canada included evidence-based decision making; bureaucracy, and regional management issues. However there were several differences that emerged from the samples that will no doubt impact on adoption of future RM therapies.

Favourable processes surrounding clinical research infrastructure, funding and ethics approval appear to have contributed to making the UK a more favourable setup than Canada for RM translation in ophthalmology in recent years. However when it comes to early use and system-wide adoption of RM therapies, the NHS was perceived to find uptake harder to manage, with local management and institutional infrastructure being perceived far more of a barrier than in Canada.

Examples of excellent management behaviours and setup in Canadian ophthalmology departments were an area which NHS management would do well to learn from. Several participants giving examples of forward thinking and innovative programmes to drive adoption and ensure Canadian clinicians bridged the gap between translation and adoption of such therapies. 
470

471

472

473

474

475

476

477

480

481

Each healthcare system is associated with national assets which could be appealing to therapy developers working in this space. Health Canada has in recent years proven itself to be a forward thinking regulator willing to look at RM therapies as exceptional technologies. In addition local healthcare providers appeared more supportive of earlier use of therapies and isolated cases uptake of RM into clinical programs. Internally in the UK, the investment and growth of Moorfields Eye Hospital whilst seen by some UK insiders as a sink for UK funding in ophthalmology, has undoubtedly given the UK a competitive advantage in basic and clinical research in RM.

As markets, single-payer healthcare systems do have some similar characteristics (Box 1) and they could have the potential to offer a "one-stop shop" for therapy developers to tackle. Ideologically, a single value system, with a uniform willingness to pay, is a far simpler proposition than that of the numerous evaluation procedures in insurance based healthcare systems. Arguably the biggest challenge in building a sustainable RM industry sector in both the UK and Canada will be in persuading decision makers to adopt truly innovative therapies which in the short term may not be cost effective, but that could give rise to a range of therapeutics which change the way we deliver healthcare.

\subsection{Future Perspective}

At current there are few authorized RM products and even fewer which have secured adoption and reimbursement. However, the resources currently being invested in RM research and development will in the near future undoubtedly yield a number of therapies, some of which may offer long-term cost savings. Ensuring there are suitable evaluation pathways, well developed routes to reimbursement, and that healthcare providers are prepared will be critical in providing a suitable adoption environment for RM. If addressed early the UK and Canada could demonstrate themselves as extremely attractive early markets for RM, to the benefit of both healthcare and inward industry investment. 


\section{Executive Summary}

498

499

500

501

502

503

504

505

506

507

508

509

510

511

512

513

514

515

516

517

518

519

520

521

522

523

524

\section{Translation}

- The UK appears to offer a favourable environment for translation of RM therapies, providing a supportive environment through investment into infrastructure.

- The Canadian research ethics process is currently a rate limiting component of the clinical trial process

\section{Early Use}

- Canadian regulators Health Canada have demonstrated a desire to move RM forward, being first to approve a number of RM therapies.

- Healthcare provider management in Canada appears to be driving innovation and adoption of new ways of working.

- The NHS's specialist commissioning group are developing new routes for adoption of therapies targeting low patient numbers $(\mathrm{CtE})$, likely to be relevant for RM therapies.

\section{System-Wide Adoption}

- The NHS is still recognised as unresponsive, and has been slow to uptake new medicines, especially struggling with disruptive innovations.

- Short term commissioning behaviours and silo budgets in the NHS could make it challenging to demonstrate to decision makers the real value of potentially "curative" treatments.

- NICE is internationally recognised as a leader in clinical guidance and technology assessment. Canada's multiple technology assessment processes are less coordinated and significantly more complex to navigate.

\section{Acknowledgements}

The authors would like to acknowledge the participant ophthalmologists for their valuable contributions in this study. In addition, the authors would like to thank K Payne, P Trueman, S Macneil, H Atkins, F, Ali, J Daniels, V Wallace, and P Archibald for useful discussions which helped shape this work. 
Future

528 This work was funded by the EPSRC through the EPSRC Doctoral Training Centre in

529 Regenerative Medicine. The authors have no other relevant affiliations or financial

530 involvement with any organization or entity with a financial interest in or financial conflict

531 with the subject matter or materials discussed in the manuscript apart from those disclosed.

532 No writing assistance was utilized in the production of this manuscript. 
1. Carr A-JF, Smart MJK, Ramsden CM, Powner MB, da Cruz L, Coffey PJ. Development of human embryonic stem cell therapies for age-related macular degeneration. Trends Neurosci. 36(7), 385-95 (2013).

2. Baylis O, Figueiredo F, Henein C, Lako M, Ahmad S. 13 Years of Cultured Limbal Epithelial Cell Therapy: A Review of the Outcomes. J. Cell. Biochem. 112(4), 993-1002 (2011).

3. Rose JB, Williams DJ. The UK relative to other single payer-dominated healthcare markets for

4. Lameire $\mathrm{N}$, Joffe $\mathrm{P}$, Wiedemann $\mathrm{M}$. Healthcare systems - an international review: an

5. House of Commons - Health Committee. The Use of New Medical Technologies within the overview. Nephrol. Dial. Transplant. 14, 3-9 (1999).

7. Kuper M, Gold SJ, Callow C, et al. Intraoperative fluid management guided by oesophageal NHS - Fifth Report of Session 2004-2005. (April), 1-29 (2005).

6. Robert G, Greenhalgh T, MacFarlane F, Peacock R. Organisational factors influencing technology adoption and assimilation in the NHS: a systematic literature review. NIHR.

8. Squires DA. The U.S. Health System in Perspective : A Comparison of Twelve Industrialized

9. Grootendorst P, Hollis A. Managing Pharmaceutical Expenditure: An overview and Options for Nations. The Commowealth Fund. Canada. .

10. For O, Sciences L. Taking Stock of Regenerative Medicine in the United Kingdom. (July) (2011).

568

569

570

11. Thomson Reuters. A bibliometric analysis of Regenerative Medicine. .

12. Streilein JW. Ocular immune privilege: therapeutic opportunities from an experiment of nature. Nat. Rev. Immunol. 3(11), 879-89 (2003).

13. Medical Research Council. A Strategy for UK Regenerative Medicine. .

14. Fields MA, Hwang J, Gong J, Cai H, Priore LV Del. The Eye as an Organ for Stem Cell Therapy. In: Stem Cell Biology and Regenerative Medicine in Ophthalmology. Tsang SH (Ed.). Springer New York, New York, NY, 1-29 (2013).

15. Poole JC, Quyyumi A a. Progenitor Cell Therapy to Treat Acute Myocardial Infarction: The Promise of High-Dose Autologous CD34(+) Bone Marrow Mononuclear Cells. Stem Cells Int. 1, 1-9 (2013).

16. Klein R, Chou C-F, Klein BEK, Zhang X, Meuer SM, Saaddine JB. Prevalence of age-related macular degeneration in the US population. Arch. Ophthalmol. 129, 75-80 (2011). 
579

580

581

582

583

584

585

586

587

588

589

590

591

592

593

594

595

596

597

598

599

600

601

602

603

604

605

606

607

608

609

610

17. Schwartz SD, Hubschman J-P, Heilwell G, et al. Embryonic stem cell trials for macular degeneration: a preliminary report. Lancet. 379, 713-20 (2012).

18. Cyranoski D. iPS cells in humans. Nat. Biotechnol. 31(9), 775-775 (2013).

19. Witzel A, Reiter H. The Problem-centered Interview. Sage, Bremen.

20. Mayring P. Qualitative Content Analysis. Forum Qual. Soc. Res. 1(2), 1-10 (2000).

21. Hackl WO, Hoerbst A, Ammenwerth E. "Why the hell do we need electronic health records?". EHR acceptance among physicians in private practice in Austria: a qualitative study. Methods Inf. Med. 50(1), 53-61 (2011).

22. Van Wilder P. Advanced Therapy Medicinal Products and Exemptions to the Regulation 1394/2007: How Confident Can We be? An Exploratory Analysis. Front. Pharmacol. 3, 12 (2012).

23. The Academy of Medical Sciences. A new pathway for the regulation and governance of health research. .

24. Cooksey D. A review of UK health research funding A review of UK health research funding. .

25. Snape K, Trembath RC, Lord GM. Translational medicine and the NIHR Biomedical Research Centre concept. QJM. 101, 901-6 (2008).

26. Wood L. NIHR Office for Clinical Research Infrastructure (NOCRI). NIHR.

27. NHS. Clinical Commissioning Groups (CCG) and how they perform [Internet]. About NHS. (2013). Available from: http://www.nhs.uk/NHSEngland/thenhs/about/Pages/ccgoutcomes.aspx.

28. NICE. Tissue-cultured limbal stem cell allograft transplantation for regrowth of corneal epithelium. (April), 1-2 (2007).

29. Ontario Health Technology Advisory Committee. Limbal Stem Cell Transplantation: OHTAC Recommendation. 8(June), 1-4 (2008).

30. NICE. Autologous pancreatic islet cell transplantation for improved glycaemic control after pancreatectomy. (April), 1-2 (2008).

31. NICE. Allogeneic pancreatic islet cell transplantation for type 1 diabetes mellitus. (April), 1-2 (2008).

32. Ontario Health Technology Advisory Committee. Islet Transplantation: An Evidence-Based Analysis. 3(4), 1-47 (2003).

33. UK Government. Government Response to the House of Lords Science and Technology Committee Inquiry into Regenerative Medicine. , 1-21 (2013). 
Figures

Table 1 Sample size and response rates for the UK and Canadian sample

\begin{tabular}{cccc}
\hline & Invited & Responded & Response Rate \\
\hline UK & 34 & 11 & $32 \%$ \\
Canada & 44 & 11 & $27 \%$ \\
\hline
\end{tabular}

617 Figure 1 Three phases of potential clinical adoption: Translation, Early use and System-wide 618 adoption.

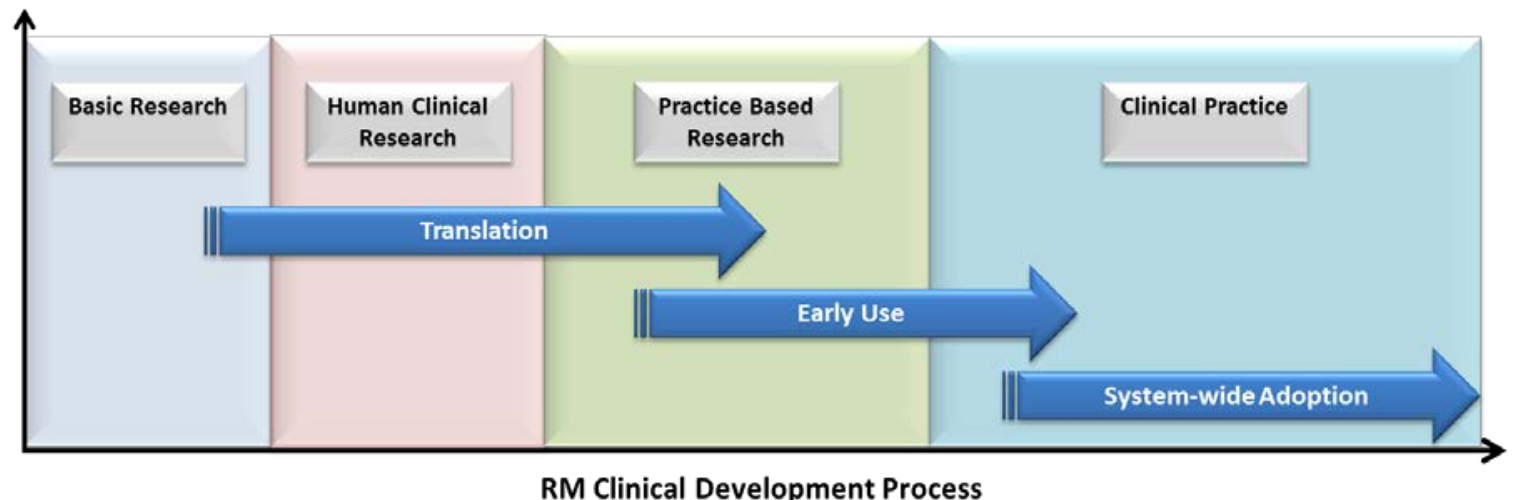

Figure 2 Recurrent themes derived from PCl, relating specifically to issues in the translation stage of clinical development. A) Pie chart representing relative contribution of themes as a percentage of total coded passages combining UK and Canadian responses. B) Bar chart representing grounded values for 5 key themes as enablers or barriers or barriers to adoption in the UK and Canada.

A

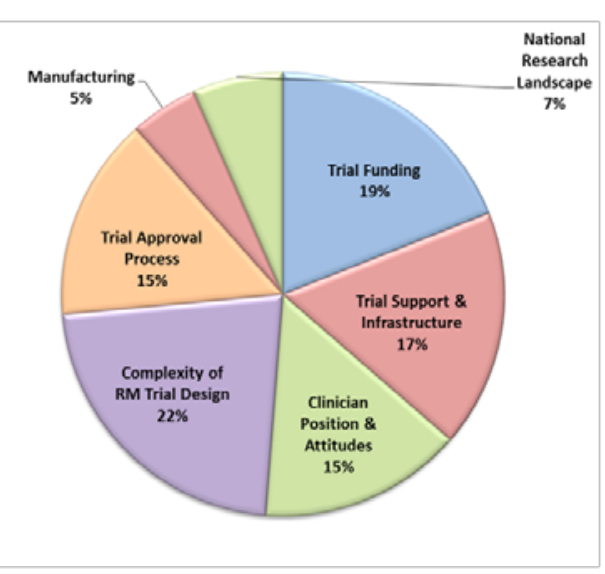

B

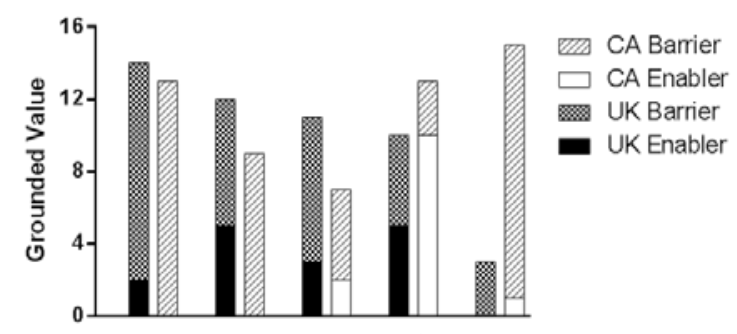

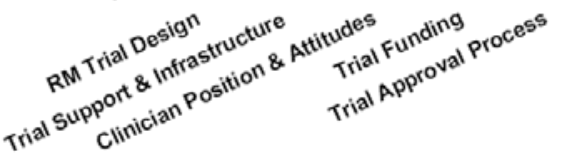


Table 2 Cell therapy trials ongoing in ophthalmology in the UK and Canada

\begin{tabular}{|c|c|c|c|c|c|}
\hline Location & Sponsor & Trial & Indication & Start & Status \\
\hline $\begin{array}{l}\text { UK, } \\
\text { Newcastle }\end{array}$ & $\begin{array}{l}\text { Newcastle } \\
\text { University }\end{array}$ & $\begin{array}{l}\text { Autologous cultured human limbal } \\
\text { epithelium for limbal stem cell } \\
\text { deficiency (ophthalmology) }\end{array}$ & $\begin{array}{l}\text { Limbal stem cell } \\
\text { deficiency }\end{array}$ & 2012 & Phase II \\
\hline $\begin{array}{l}\text { UK, } \\
\text { Edinburgh }\end{array}$ & $\begin{array}{l}\text { Edinburgh } \\
\text { University, } \\
\text { Scottish } \\
\text { National Blood } \\
\text { Transfusion } \\
\text { Service }\end{array}$ & $\begin{array}{l}\text { Corneal stem cells (allogeneic } \\
\text { limbal epithelial stem cells on } \\
\text { amniotic membrane) }\end{array}$ & $\begin{array}{l}\text { Limbal stem cell } \\
\text { deficiency }\end{array}$ & 2011 & $\begin{array}{l}\text { Phase I } \\
\text { /II }\end{array}$ \\
\hline $\begin{array}{l}\text { UK, } \\
\text { London } \\
\text { Edinburgh }\end{array}$ & $\begin{array}{l}\text { Advanced Cell } \\
\text { Technologies }\end{array}$ & $\begin{array}{l}\text { Retinal pigment epithelial cell } \\
\text { replacement for Stargardt's } \\
\text { disease }\end{array}$ & $\begin{array}{l}\text { Stargardt's } \\
\text { disease }\end{array}$ & 2011 & $\begin{array}{l}\text { Phase I } \\
\text { /II }\end{array}$ \\
\hline $\begin{array}{l}\text { UK, } \\
\text { London }\end{array}$ & Pfizer & $\begin{array}{l}\text { A Study Of Implantation Of Human } \\
\text { Embryonic Stem Cell Derived } \\
\text { Retinal Pigment Epithelium In } \\
\text { Subjects With Acute Wet Age } \\
\text { Related Macular Degeneration } \\
\text { And Recent Rapid Vision Decline }\end{array}$ & $\begin{array}{l}\text { Acute wet Age } \\
\text { related Macular } \\
\text { Degeneration }\end{array}$ & 2014 & Phase I \\
\hline $\begin{array}{l}\text { Canada, } \\
\text { Quebec }\end{array}$ & CHU de Québec & $\begin{array}{l}\text { Autologous Cultured Corneal } \\
\text { Epithelium (CECA) for the } \\
\text { Treatment of Limbal Stem } \\
\text { Cell Deficiency }\end{array}$ & $\begin{array}{l}\text { Limbal stem cell } \\
\text { deficiency }\end{array}$ & 2012 & $\begin{array}{l}\text { Phase I } \\
\text { /II }\end{array}$ \\
\hline
\end{tabular}

Figure 3 Recurrent themes derived from PCl, relating specifically to issues in the early use of RM passages combining UK and Canadian responses. B) Bar chart representing grounded values for 5

A

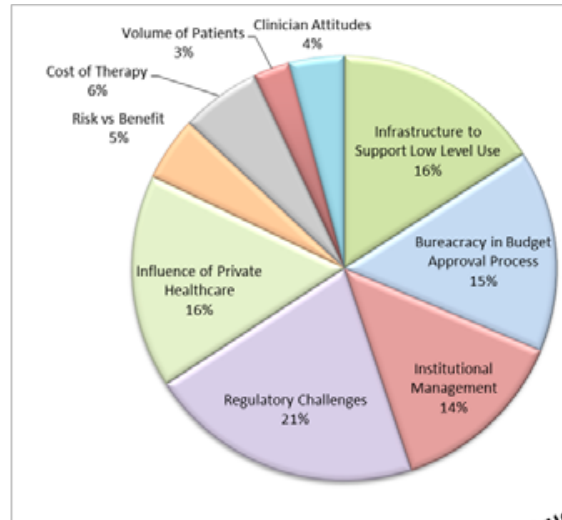

B

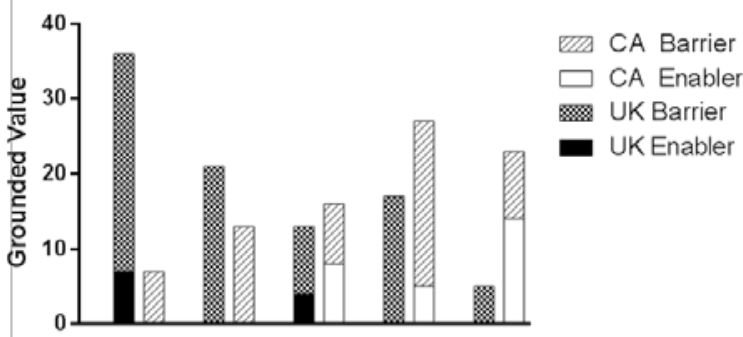




\section{Medicine}

637

638

639

640

641

642

Figure 4 A) Schematic of differences in in health system organisation between Canada and UK P\&R: Pricing and Reimbursement; HTA: Health Technology Assessment. B and C) Recurrent themes derived from $\mathrm{PCl}$, relating specifically to issues in the system-wide adoption of RM therapies. A) Pie chart representing relative contribution of themes as a percentage of total coded passages combining UK and Canadian responses. B) Bar chart representing grounded values for 5 key themes as enablers or barriers or barriers to adoption in the UK and Canada.

A
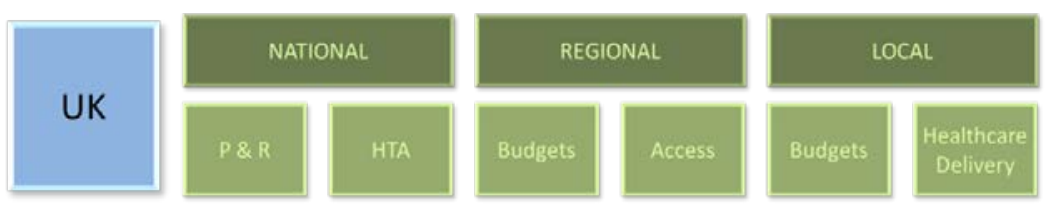

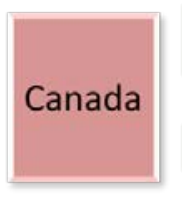

NATIONAL

B

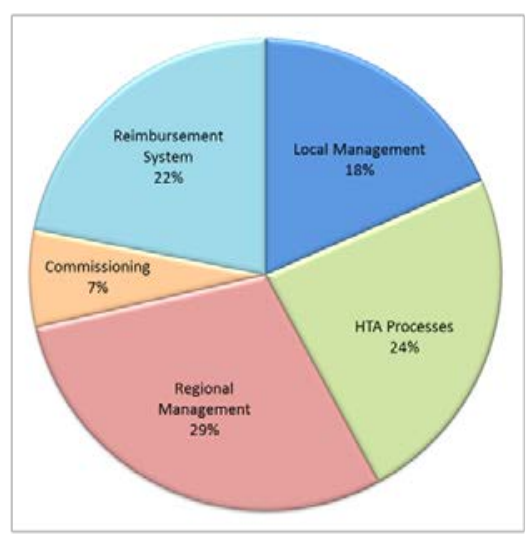

C

PROVINCIAL

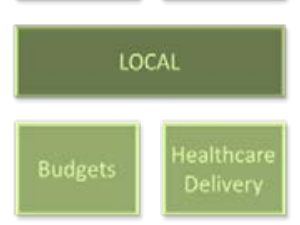




\section{Table 4 Comparison of Healthcare in UK and Canada}

\begin{tabular}{ll}
\hline \multicolumn{1}{c}{ UK } & \\
\hline Universal Health Care & Universal Health Care \\
\hline Publically funded & Publically funded \\
\hline Publically delivered & Privately delivered \\
\hline 212 CCGs, directly answerable to Dept. of Health & 10 autonomous Provincial Ministries \\
\hline $\begin{array}{l}\text { Physicians salaried } \\
\text { Increasing level of patient choice but referral based on } \\
\text { physician availability }\end{array}$ & $\begin{array}{l}\text { Healthcare is Semi-competitive for high volume, well } \\
\text { reimbursed procedures (cataracts etc.) }\end{array}$ \\
\hline NICE commissions HTA & HTA carried out at national, provincial and local levels \\
\hline $\begin{array}{l}\text { Patented drug prices agreed through designated pricing } \\
\text { groups (PPRS) }\end{array}$ & $\begin{array}{l}\text { High prices for patented pharmaceuticals varying from } \\
\text { province to province }\end{array}$ \\
\hline $\begin{array}{l}\text { 9.6\% GDP spent on healthcare annually } \\
\text { f2170 spent on healthcare per capita }\end{array}$ & $\begin{array}{l}11.9 \% \text { GDP spent on healthcare annually } \\
£ 3240 \text { spent on healthcare per capita }\end{array}$ \\
\hline
\end{tabular}

Table 5: Overview of key comparative points emerging from interview data

\begin{tabular}{|c|c|c|}
\hline Phase & UK & Canada \\
\hline \multirow[t]{2}{*}{ Translation } & $\uparrow$ Single national ethics approval & $\downarrow$ Prohibitively slow ethics review process \\
\hline & $\begin{array}{l}\text { 个 Significant investment into trial } \\
\text { infrastructure through NIHR }\end{array}$ & $\begin{array}{l}\leftrightarrow \text { Limited support and funding for } \\
\text { translational research }\end{array}$ \\
\hline \multirow[t]{3}{*}{ Early Use } & $\leftrightarrow$ Regulated as ATMPs under EMA & $\begin{array}{l}\uparrow \text { Forward looking regulator, willing to look } \\
\text { at RMs as exceptional therapies }\end{array}$ \\
\hline & $\begin{array}{l}\downarrow \text { Management attitudes a barrier in some } \\
\text { institutions }\end{array}$ & $\begin{array}{l}\uparrow \text { Examples of outstanding leadership in } \\
\text { institutional management }\end{array}$ \\
\hline & $\begin{array}{l}\text { 个 Specialist commissioning routes being } \\
\text { developed for RM. }\end{array}$ & $\begin{array}{l}\leftrightarrow \text { RM will fit into normal commissioning } \\
\text { pathways }\end{array}$ \\
\hline \multirow[t]{3}{*}{$\begin{array}{l}\text { System-Wide } \\
\text { Adoption }\end{array}$} & $\begin{array}{l}\downarrow \text { Unresponsive organisation slow to instil } \\
\text { changes }\end{array}$ & $\begin{array}{l}\text { 个 Several small responsive healthcare } \\
\text { organisations with well-defined patient needs }\end{array}$ \\
\hline & $\begin{array}{l}\downarrow \text { At current short term commissioning } \\
\text { behaviours, and "silo budgets" }\end{array}$ & $\begin{array}{l}\leftrightarrow \text { Signs of movement towards long term } \\
\text { "continuity of care" models }\end{array}$ \\
\hline & $\begin{array}{l}\uparrow \text { Single national assessment of cost } \\
\text { effectiveness -internationally referenced }\end{array}$ & $\begin{array}{l}\leftrightarrow \text { Provincial variations with highly variable } \\
\text { HTA processes }\end{array}$ \\
\hline
\end{tabular}



interviews)

Characteristics of Single Payer HealthCare Markets

- $\quad$ Driven by cost-effectiveness

- Decisions made on quantity and quality of evidence

- Systems are able to offer an economic threshold for life

- More rational, more consistent discussions over pricing

- Opaque budget approval processes, widely varied by region

- Less likely to give reimbursement for marginal improvements,

- Potential to offer continuity of care

- Clinical trials may benefit from access to entire patient populations 